\title{
Pharmacological Aspects of Neurorehabilitation
}

\section{(ㄷ) (i) (우) $\Theta$}

\author{
Author \\ Volker Hömberg
}

\author{
Affiliation \\ SRH Gesundheitszentrum Bad Wimpfen \\ Key words \\ neurorehabilitation, pharmacology, brain recovery, \\ neuroprotection, detrimental drugs \\ Bibliography \\ DOI http://dx.doi.org/10.1055/s-0043-116338 \\ Neurology International Open 2017; 1: E247-E255 \\ (c) Georg Thieme Verlag KG Stuttgart · New York \\ ISSN 2511-1795 \\ Correspondence \\ Prof. Dr. Volker Hömberg \\ SRH Gesundheitszentrum Bad Wimpfen \\ Bei der alten Saline 2 \\ 74206 Bad Wimpfen \\ Germany \\ Volker.Hoemberg@gbw.srh.de
}

\section{ABSTRACT}

Physicians in neurorehabilitation often deal with pharmacological problems, marshalling antihypertensive, anticonvulsive and anticoagulation treatments. In addition, there is growing interest in positive or negative effects of medication on brain recovery. Of great importance is the concept of so-called "detrimental drugs" known to negatively influence processes of brain reorganization and recovery. To this group belong anti-convulsive agents such as phenytoin and barbiturates as well as benzodiazepines, butyrophynones and the antihypertensives clonidine and prazosine. Whenever possible these drugs should be avoided in the course of brain recovery after a cerebral lesion.

For only two substances (the SSRI fluoxetine and cerebrolysin, a mixture of pleotropic neuropeptides and amino acids) large randomized controlled trials showed a positive influence on facilitating motor recovery after the stroke. Both substances probably work through pleotropic multiple molecular mechanisms and not as a one-to-one agonist on the receptor. In general the use of antidepressive agents especially SSRI after the stroke can also be recommended for non-depressed stroke patients.

Also dopaminergic drugs have been shown in smaller studies to positively influence functional recovery. Considering their low side-effect profile, the tentative use of $100 \mathrm{mg}$ of L-Dopa per day in the subacute phase of the stroke can be recommended. In MS patients the use of antidepressive agents is also recommend to improve life quality.

In patients with diminished states of consciousness amantadine is the only substance which a randomized controlled study proved to have at least some transient effect. The use of amantadine can be recommended for the improvement of the level of consciousness in these patients.

\section{Introduction}

Physicians engaged in neurological rehabilitation constantly have to deal with aspects of primary pharmacological treatment of patients, including control of high blood pressure, anticonvulsive therapies and suitable anticoagulation treatment to reduce risk factors and secondary problems. Furthermore, neurological rehabilitation must also take into account pharmacological issues relating to restoration of brain function. This concerns the avoidance of pharmaceuticals that may interfere with brain recovery as well as the use of drugs that may have a positive affect on brain function. This overview aims to provide a critical summary of the options available to the clinician in the pharmacological treatment of patients after acute neurological events as part of the process of the rehabilitation of brain organization and restoration of brain function, as well as discuss the avoidance of potentially negative effects of pharmacological interventions.

\section{General pharmacology of restoration of brain function}

There are good animal-experimental data for numerous commonly-used drugs regarding their influence of spontaneous brain recovery after acute neuronal damage.

These data were developed based on experimental trauma or ischemia models. The models [1-5] convincingly demonstrated that as a rule amphetamines significantly improved motor and perceptual functions [6-8]. Amphetamines demonstrate an inverse U-shaped relationship with an optimal effect at medium doses, and their use depends on parallel, task-related behavior. As a rule they are blocked by haloperidol [9-11].

The likely action mechanism of action of amphetamines is the central release of norepinephrine [12,13]. 
- Table 1 Parallel effects of individual substances on function recovery or long-term potential (LTP).

\begin{tabular}{|l|c|c|}
\hline \multicolumn{1}{|c|}{ Substance } & $\begin{array}{c}\text { Effect on function } \\
\text { recovery }\end{array}$ & Effect on LTP \\
\hline Norepinephrine & + & + \\
\hline Amphetamine & + & + \\
\hline Clonidine & - & - \\
\hline Prazosin & - & $?$ \\
\hline Haloperidol & - & - \\
\hline Propanolol & 0 & - \\
\hline GABA & - & - \\
\hline Diazepam & - & - \\
\hline Muscimol & - & + \\
\hline Phenytoin & - & - \\
\hline ACH & + & \\
\hline Scopolamine & - & \\
\hline+ +: Promoted effect & & \\
\hline $0:$ No effect & & \\
\hline -: Reduced effect & & \\
\hline
\end{tabular}

- Table 2 List of so-called detrimental drugs (substances inhibiting restoration of brain function).

\begin{tabular}{|l|l|}
\hline Detrimental drugs & \\
\hline Haloperidol & D2 antagonist \\
\hline Prazosin & Alpha-1 antagonist \\
\hline Clonidine & Alpha-2 agonist \\
\hline Phenytoin & GABA mechanism \\
\hline Benzodiazepines & GABA agonist \\
\hline Phenobarbital & GABA mechanism \\
\hline
\end{tabular}

Other sympathomimetic substances such as methylphenidate and alpha- 2 antagonists including yohimbine and idazoxane also increase norepinephrine release and lead to an improvement in brain function recovery. Conversely, alpha-2 agonists such as clonidine or alpha- 1 antagonists such as prazosin may interfere with brain function restoration [14]-[15].

Haloperidol and other butyrophenones show a considerable disruption of spontaneous brain recovery in all experiments and can antagonize the effect of amphetamines [9, 10, 16, 17]. In contrast, classical tricyclic antidepressants such as clomipramine or imipramine show only neutral or slightly negative influences on brain recovery.

In animal experiments, serotonin reuptake inhibitors (SSRI) such as trazodone or fluoxetine have neutral or slightly positive effects on brain function recovery [18]. Significantly negative effects can be described for most GABAergic substances, especially for benzodiazepines [19-21].
The same applies to many classical anticonvulsant substances such as phenytoin and barbiturates [22,23]. It has long been known that they can adversely affect spontaneous brain recovery, probably via GABAergic mechanisms [24, 25]. After experimental infarctions, anticholinergics have also been shown to disrupt motor recovery. On the other hand, carbamazepine does not appear to influence recovery mechanisms.

It is not entirely clear which molecular mechanisms in the indicated substances are responsible for promoting or inhibiting restoration of brain function. It is highly likely that influences on longterm potential (LTP) play an essential role in this regard. As shown in $>$ Table 1, there is a clear parallel between the effects of some substances influencing the brain recovery function and their effect on LTP as demonstrated in animal experiments [26].

\section{The "detrimental drug" concept}

Many of the above-mentioned pharmacologically active brain function-enhancing drugs are still uncritically used in everyday clinical situations in patients after suffering severe cerebral lesions.

Larry Goldstein was the first to use introduce the concept of socalled detrimental drugs [27].

In catamnestic studies he showed that after brain injury, patients receiving one of the substances listed in $>$ Table 2 showed significantly worse functional end results after months or years of treatment compared to patients who were not treated with any substances which might potentially damage brain organization. It cannot be ruled out with certainty that these effects are based on selection bias, since it is possible that the patients treated with detrimental drugs had more severe brain damage.

The data on the use of detrimental drugs is, of course, inconsistent, and recommendations are based essentially on animal-experimental data. Randomized controlled studies are lacking completely and are probably not ethically justified as well.

Nevertheless, it is advisable to dispense with these substance classes in clinical practice in the acute and post-acute phase after stroke, cerebral trauma and other brain injury. Today it is highly likely that ruling out detrimental drugs is clinically more important than administration of substances promoting brain reorganization.

\section{Substances improving restoration of brain function}

\section{Amphetamines}

Various substances influencing monaminergic transmission have been used experimentally to improve brain function. After the early animal experiments of Feeney and colleagues [9], there was great interest in introducing amphetamines into clinical practice in order to positively influence brain function recovery procedures. This has been supported by several experimental studies in humans showing that amphetamines increase the capacity of motor learning [28] and, for example, sensitive two-point discrimination in normal subjects [29].

In 1988, Chrisostomo et al. [30] performed an initial study of only 8 patients which showed some positive effects of amphetamines on patients in the subacute phase post-stroke.

Larger studies have shown varying and unconvincing results [31-42]. Therefore, many open questions remain regarding the use of amphetamines, e. g. dosage at which the amphetamine com- 
ponents should be used, at which time and for what duration in the acute or subacute or chronic phase after stroke. Therefore, the question of the usefulness of amphetamines cannot be conclusively clarified, and there is no recommendation regarding amphetamines during the subacute or chronic phase after stroke.

At the moment it can be said that although the use of amphetamines has some potential to improve brain function recovery after stroke, clinical use cannot be recommended with respect to motor or cognitive functions.

\section{Dopaminergics}

Levodopa is a pharmacologically "dirty" substance because it affects not only dopaminergic but also partially influences noradrenergic neurotransmission. A first randomized controlled study by Scheidtmann et al. [43] compared 22 stroke patients treated with levodopa with 25 receiving a placebo; the results was that using levodopa resulted in an increase in motor function (dose: $100 \mathrm{mg}$ L-Dopa for 6 weeks after onset).

It is unclear to what extent the efficacy of dopaminergics depends on the duration of the dose after an acute lesion. Perhaps longer-term administration of a few weeks after an acute event is more promising than a too short administration of the drugs. Of course, a final clarification of this issue is only possible through systematic prospective randomized trials.

This finding of dopaminergics could not be confirmed in subacute to chronic stroke patients who received L-Dopa for 9 weeks [44].

It was demonstrated that L-Dopa improved the learning of word lists by acute stroke patients compared to those receiving a placebo [45]. Likewise, Senlow et al. [46] showed that patients receiving L-Dopa prior to the start of speech therapy showed improved speech recovery (word fluency and repetition of word lists). On the other hand, Leeman et al. [47], in a crossover trial of subacute administration of L-Dopa for 2 weeks indicated no positive effects on speech recovery.

Restemeyer et al. [48] observed no significant effect of a single dose of L-Dopa on motor recovery and motor excitability in chronic stroke patients. In a long-term administration of L-Dopa in chronic stroke patients, Lokk et al. [49] showed that four-week administration of L-Dopa with a single daily dose improved motor performance. Similar results as in the Scheidtmann et al. study were confirmed in a study by Masihuzzaman et al. [50]. In a case control design, stroke patients were either randomized to physiotherapy in combination with L-Dopa or physiotherapy alone with placebo for 8 weeks. The L-Dopa group showed greater improvement in the Rivermead Mobility Index.

Further studies [51-54] have investigated the outcome of L-Dopa in combination with physiotherapy in chronic stroke patients years after the stroke event. Various study designs have shown somewhat positive effects. The 2005 study by Floel et al. [53] demonstrated positive effects using transcranial magnetic stimulation indicated potentials but no clinical effects. Restemeyer's study [48] indicated no positive clinical effects while other studies with different designs reflected positive effects on motor learning and various motor scores [51, 52, 54]. It should be emphasized that all these studies of chronic patients were based on very small samples (only up to 18 patients).
There are currently no studies of dopaminergic facilitation using robot-assisted therapy or virtual reality. Recently Tran et al. [55] published a positive review of the utilization of dopaminergics.

In summary it can be stated that there is some evidence that positive results can be achieved by daily dosages of $100 \mathrm{mg}$ of LDopa in both subacute and chronic stroke patients if administered over the course of at least one week. A final decision on effectiveness cannot be made at this time, however, and thus there is no clear recommendation to use L-Dopa. However, in view of the low potential for side effects, administering L-Dopa can be useful.

\section{Reboxetine}

Reboxetine is a selective norepinephrine reuptake inhibitor approved for treating depression. Based on its pharmacological profile it can be assumed that this substance has properties similar to amphetamines in the facilitation of noradrenergic neurotransmission. Considering that reboxetine has very few side effects compared to amphetamines (no addiction potential, little pulmonary risk), this substance can be regarded as useful for improving brain function recovery. Initial investigations showed positive effects on restoration of motor-related brain function $[56,57]$.

\section{Methylphenidate}

Methylphenidate is a commonly used psycho-stimulant in the treatment of attention deficit disorder (ADD)/hyperactivity problems. This is a piperidine component that increases the concentration of dopamine and norepinephrine by inhibiting multiple monomial transporters.

Numerous studies have investigated a possible effect of methylphenidate on cognitive recovery after stroke and brain trauma [58-60]. Early administration of methylphenidate after severe cerebral trauma could shorten the length of stay in the intensive care unit [61].

Most of the studies with methylphenidate were limited to very small groups of patients, so that definite conclusions on its fundamental efficacy cannot currently be made.

\section{Amantadine}

Amantadine is a substance with various pharmacological characteristics, such as increasing the release of striatial dopamine, retarding dopamine reuptake while increasing the number of postsynaptic dopamine receptors. Furthermore, amantadine stimulates DOPA decarboxylase in the striatum while acting as a weak noncompetitive NMDA glutamate receptor antagonist similar to memantine, often used in the treatment of degenerative dementia [62].

Amantadine was first introduced as an antiviral substance, especially against influenza viruses [63]; it was subsequently discovered that amantadine also had a positive effect on parkinsonian symptoms [64].

Smaller experimental studies suggested a positive effect of amantadine on improving states of restricted consciousness in cerebral trauma [65-70].

In an open study, Kraus et al. [67] demonstrated a significant improvement of executive functions by administering amantadine 
- Table 3 List of antidepressive effects on various monaminergic transmitter systems.

\begin{tabular}{|c|c|c|c|c|c|}
\hline NA reuptake inhibitor & $\begin{array}{l}\text { 5-HT reuptake } \\
\text { inhibitor }\end{array}$ & MAO inhibitor & Alpha-2 blocker & $5-\mathrm{HT}_{1 \mathrm{~A}}$ activator & $\begin{array}{l}\text { 5-HT reuptake } \\
\text { activator (tianeptine) }\end{array}$ \\
\hline \multicolumn{6}{|l|}{ Adaptive Changes } \\
\hline Beta down-regulation & $\begin{array}{l}\text { Alpha-1 up- } \\
\text { regulation }\end{array}$ & $\begin{array}{l}5-\mathrm{HT}_{2} \text { down- } \\
\text { regulation }\end{array}$ & $\begin{array}{l}5-\mathrm{HT}_{1} \text { sensitivity } \\
\text { increase }\end{array}$ & $\begin{array}{l}D_{2} \text { sensitivity } \\
\text { increase }\end{array}$ & $\mathrm{D}_{1}$ down-regulation \\
\hline \multicolumn{6}{|l|}{ NA: Norepinephrine } \\
\hline \multicolumn{6}{|l|}{ 5-HT: Serotonin } \\
\hline \multicolumn{6}{|c|}{ MAO: Monoaminoxydase } \\
\hline \multicolumn{6}{|c|}{$\mathrm{D}_{2}$ : Dopamine-2 receptors } \\
\hline $\mathrm{D}_{1}$ : Dopamine-1 recep & & & & & \\
\hline
\end{tabular}

to SHT patients, combined with a distinct increase in left-hemispheric prefrontal glucose metabolism in PET studies.

Giacino et al. [71] in a methodically high-value placebo-controlled double-blind, multi-center investigation of 184 patients with various pronounced states of limited consciousness (non-responsive and minimally-responsive wakefulness state) demonstrated that in comparison to the placebo group, recovery of patients receiving amantadine during a 4-week interval was accelerated. After amantadine was discontinued, however, the recovery slowed down so that after a total of 6 weeks, both groups exhibited similar results. Likewise, irritability after SHT is positively influenced by amantadine [72].

It is also currently too early to derive definitive conclusions regarding this substance. The large study by Giacino [71] did show, however, that amantadine has a demonstrable therapeutic potential, particularly for patients in a state of limited consciousness.

\section{Piracetam}

Piracetam is a nootropic substance frequently used to treat dementia, and chemically is a derivate of $\gamma$-aminobutyric acid. With respect to neurorehabilitation, this substance is interesting beyond treating dementia, since several randomized controlled studies have demonstrated its effect in the treatment of patients with severe aphasia [73-75]. This has likewise been confirmed by a Cochrane review [76].

The exact mode of action is unclear, but its effect on AMPA and NMDA glutamate receptors is likely. It is not possible to derive reliable dosage data based on the literature, since dosages varied from $4.8 \mathrm{~g} /$ day $[73,77]$ to $12 \mathrm{~g} /$ day [78].

From the clinical point of view, it is certainly helpful to use the substance in high intravenous doses ( $12 \mathrm{~g}$ per day) in the acute/ subacute phase in patients with severe to moderate aphasia.

\section{Anti-depressants}

Depression is a common secondary problem in patients after stroke and cranial trauma which can significantly affect their cognitive and motor abilities [79].
The frequency of depression after stroke has been indicated to be $60 \%$ or more [80]. In the mid-1980s, Reding was the first [81] in the USA to show that treating depression in stroke patients not only improved their depression, but also had a positive effect on the rehabilitation process. Several placebo-controlled studies have shown that the administration of antidepressants such as trazodone resulted in significantly better function recovery measured by relevant scores and also resulted in an improvement of ADL activities compared to using a placebo.

Dam et al. [82] demonstrated that the use of serotonin reuptake inhibitors such as fluoxetine and maprotiline resulted in improved motor recovery in stroke patients. Early use of antidepressants particularly resulted in improvement of cognition [83]. In addition, early treatment with antidepressants after stroke (within the first 12 weeks) showed a significant increase in life expectancy [84]. This applies to depressive and non-depressive patients alike. The mechanisms contributing to this improvement in life expectancy resulting from early treatment with antidepressants are unclear.

Chollet and colleagues [85] then performed the best evidencebased study of motor recovery after acute stroke according to EBM criteria. Their FLAME trial treated a total of 118 patients suffering from severe motor deficits with fluoxetine ( $20 \mathrm{mg}$ daily) or a placebo for 3 months, starting 5-10 days post-stroke. Twenty days after treatment, motor scores showed an improved recovery of function using fluoxetine as compared to placebo.

Multiple mechanisms contribute to the positive effect of antidepressant drugs on motor and cognitive recovery after stroke.

Improving their mood can result in patients being more willing and motivated to participate in rehabilitation therapies. In addition, there is probably a more complex influence of antidepressants on brain function recovery which goes beyond pure 1:1 transmitter-receptor interaction. It has been known for many years that antidepressants also develop their "classic" antidepressant effect only weeks after the start of the treatment. The cause is certainly a complex intervention of the antidepressants in the mechanisms of brain reorganization, and therefore not only in the stroke treatment itself, but also with respect to normal endogenous depression. Manifold molecular mechanisms play a role in this (see $>$ Table 3). 
It is not certain which group of antidepressants has the best effect on restoration of brain function. It is notable that substances with very different monaminergic efficacy have similar antidepressant properties. These include serotonin reuptake inhibitors, as well as serotonin reuptake blockers, which tend to lead to serotonin reduction rather than an increase [86]. Tianeptine, which lowers the serotonin concentration of receptors shows, for example, in addition to an antidepressive effect, definite reorganisational effects on stress-induced morphological changes in the hippocampus in animal models [87]. Thus tianeptine is possibly an interesting candidate for to promote brain recovery, but there are no related studies to date.

The TALOS-Trial in Denmark (so far published only as abstract) showed in a population of 642 stroke patients no significant effect of citalopram compared to placebo on brain recovery. There was only a slight statistical tendency for some functional improvement. Further large clinical studies (FOKUS AFFINITY EFFECT) are underway to clarify the effect of Fluoxetin on functional recovery 6 months after stroke in more than 6000 patients. Results are expected in 2018.

With respect to use of antidepressants, it can be stated that a higher-quality study following EBM criteria demonstrated that fluoxetine has a definite effect on promoting restoration of brain function after a stroke.

\section{Depression and Multiple Sclerosis}

Many MS patients do not always immediately experience noticeable depression and should be treated with antidepressants after careful psychometric examination. The prevalence among depression among MS patients is between 47 and $54 \%$ [88], and the risk of suicide among these patients is twice as high compared to the normal population [89].

\section{Impaired Consciousness}

Various classes of substances have been used experimentally to improve the level of consciousness in patients who are unresponsive or exhibit minimal alertness. A positive effect has been shown in several small studies of amantadine [90-94].

A larger multi-centric randomized study demonstrated that amantadine was also effective following EBM criteria, even if only for a short period [71].

Somewhat positive effects were demonstrated for L-Dopa in smaller samples. Likewise, brain reorganization effects of other dopamine agonists such as pramipexole and bromocriptine were shown in small samples [94-97]. However, the dosage and duration of L-Dopa administration remains unclear.

Individual studies of pump-administered apomorphine indicated positive effects [98]. In a larger study of 80 patients, methylphenidate was shown to shorten the length of stay in intensive care as well as the entire length of hospitalization for those suffering from severe traumatic brain trauma [61]. However, Martin and Whyte in a study of 22 patients found that methylphenidate had no positive effects on improving consciousness [99]. Small studies have also shown positive effects for antidepressants such as sertraline [100] or classical tricyclic antidepressants such as amitripty- line [101]. Modafinil, a substance used predominantly for the treatment of parasomnia, has also shown some positive effects [102], but these were not confirmed by larger sample sizes [103].

Interestingly, the so-called "Z-drugs" such as zopiclone and zolpidem, which are normally used for sleep stimulation and / or treating insomnia, show apparently paradoxical arousal effects. However such effects have only been observed in individual cases of coma treatment [104-109]. Due to the minimal potential for side effects, trial use of zolpidem for a few days may be useful for patients with unresponsive wakefulness as well as minimal conscious state (minimal responsive wakefulness).

In summary, apart from amantadine, a positive effect on the elevation of consciousness in states of restricted consciousness has not yet been demonstrated with sufficient certainty for any substance.

\section{Fatigue}

For MS patients fatigue is a particularly significant problem. Despite initial positive-appearing reports on the use of modafinil [110], its effects were not confirmed in further studies [111]. Likewise, other neurostimulants such as pemoline [112] and amantadine, as well as individual case observations on the potassium channel blocker fampridine, occasionally demonstrated effects [113-117]. Meta-analyses, however, could not confirm these results [118]. Taking alfacalcidol, an analog of vitamin D, may provide better effects [119]. Problems of treating fatigue in MS patients was recently extensively treated in a review [120].

\section{Neuroprotective Substances}

Despite good results in numerous animal experiments, the use of supposedly neuroprotective substances such as NMDA, AMPA receptor blockers, or calcium antagonists, etc., has been very disappointing. Despite hundreds of millions of dollars spent on in various studies, the results were generally completely negative [121-123].

Rogalewski et al. [123] had pointed out that the use of unimodal substances, that is, those acting on a 1:1 receptor-transmodal basis were less effective in achieving neuroprotective or neuroregenerative effects after stroke or cerebral trauma compared to pleiotropic multimodal substances.

Our recently published CARS trial using cerebrolysin was the first meaningful study following EBM criteria to demonstrate a verifiable clinically significant effect on stroke recovery when cerebrolysin was used during the subacute stage [124]. Among a total of 208 randomized patients, we were able to show that protracted administration of cerebrolysin ( $30 \mathrm{ml}$ IV over 21 days) in combination with physiotherapy in the subacute phase (start of treatment 24-72 hours after onset) had a significant effect in an impairment measurement test (ARAT) even after three months post-stroke.

Cerebrolysin is a standardized mixture of low molecular weight neuropeptides and free amino acids and is thus a pleiotropic multimodal substance that can affect a variety of molecular processes of brain function repair.

Of course, this initial large study requires further substantiation by further investigations, especially when earlier studies, although smaller, showed only slight effects of the substance, e. g. [125, 126]. 
Cerebrolysin is certainly not a cure-all or even comparable to the legendary "heavenly drug" Therial of antiquity and Middle Ages which likewise consisted of a mixture of over 70 substances (see [127]).

To date cerebrolysin has not been approved as a medication in Germany.

\section{Clinical Relevance}

1. Selection of medication in patients in the subacute phase after stroke and cranial brain trauma should take into account basic aspects of the pharmacology of brain reorganization. In particular, so-called detrimental drugs should be avoided whenever possible and replaced by less harmful medications. This applies in particular to the use of certain anti-hypertensive and classical anticonvulsant substances such as phenytoin and barbiturates, but especially benzodiazepines and butyrophenones.

2. The use of antidepressants, in particular SSRIs, can also be recommended for the improvement of cerebral reorganization in non-depressed stroke patients as well.

3. The use of amantadine can be recommended to improve the level of consciousness in patients with impaired consciousness (non-responsive or minimal responsive alertness).

4. Of all the neuroprotective drugs, only the multimodal substance cerebrolysin has been shown to be clinically significant in the recovery of motor function in subacute stroke patients.

\section{Conflict of Interest:}

V. Hömberg has received honoraria from Ever Neuropharma Austria.

\section{References}

[1] Meyer PM, Hotel JA, Meyer DR. Effects of dl-amphetamine upon placing responses in neodecorticate cats. J Comp Physiol Psychol 1963; 56: 402-404

[2] Beeney DM, Gonzalez A, Law WA. Amphetamine restores locomotor function after motor cortex injury in the rat. Proc West Parmacol Soc 1981; 24: 15-17

[3] Hovda DA, Feeney DM. Amphetamine with experience promotes recovery of locomotor function after unilateral frontal cortex injury in the cat. Brain Res 1984; 298: 358-361

[4] Sutton RL, Feeney Dm. a-Noraderenergic agonists and antagonists affect recovery and maintenance of beam-walking ability after sensorimotor cortex ablation the rat. Restaurative Neurology and Neuroscience 1992; 4: 1-11

[5] Stroemer RP, Kent TA, Huelebosch CE. Enhanced neocortical neural sprouting, synaptogenesis, and behavioural recovery with D-amphetamine therapy after neocortical infartion in rats. Stroke 1998; 29: 2381-2395

[6] Hovda DA, Feeney DM. Haloperidol blocks amphetamine induced recovery of binocular depth perception after bilateral visual cortex ablation in the cat. Proc West Pharmacol Soc 1985; 28: 209-211

[7] Feeney DM, Hovda DA. Reinstatement of binocular depth perception. Brain Res 1985; 342: 352-356
[8] Hovda DA, Sutton RL, Feeney DM. Amphetamine induced recovery of visual clift performance after bilateral visual cortex ablation in cats: Measurements of. Behav Neurosci 1989; 103: 574-584

[9] Feeney DM, Gonzalez A, Law WA. Amphetamine, haloperidol and experience interact to affect rate of recovery after motor cortex injury. Science 1982; 217: 855-857

[10] Hovda DA, Feeney DM. Haloperidol blocks amphetamine induced recovery of binocular depth perception after bilateral visual cortex ablation in the cat. Proc West Pharmacol Soc 1985; 28: 209-211

[11] Goldstein LB, Davis JN. Post lesion practice and amphetamine-facilitated recovery of beam-walking in the rat. Restor Neurol Neurosci 1990; 2: $311-314$

[12] Plewnia C, Hoppe J, cohen LG et al. Improved motor skill acquisition after selective stimulation of central norepinephrine. Neurology 2004; 62-2124-2126

[13] Feeney DM, Westerberg VS. Norepinephrine and brain damage: alpha noradrenergic pharmacology alters functional recovery after cortical trauma. Can J Psychol 1990; 44: 233-252

[14] Goldstein LB, Davis JN. Clonidine impairs recovery of beam-walking in rats. Brain Res 1990; 508: 305-309

[15] Stephens J, Goldberg G, Demopoulos JT. Clonidine reinstates deficits following recovery from sensorimonor cortex lesion in rats. Arch Phys Med Rehabil 1986; 67: 666-667

[16] Baviera M, Invernizzi RW, Carli M. Haloperidol and clozapine have dissociable effects in a model of attentional performance deficits induced by blockade of NMDA receptors in the MPFC. Psychopharmacology (Gerl) 2008; 196: 269-280

[17] Goldstein LB, Bullman S. Differential effects of haloperidol and clozapine on motor recovery after sensorimontor cortex injury in rats. Neurorehabil neural Repair 2002; 16: 321-325

[18] Pariente J, Loubinoux I, Carel $C$ et al. Fluoxetine modulates performance and cerebral activation of patiens recovering from stroke. Ann Neurol 2001; 50: 718-729

[19] Chweh AQ, Swinyard EA, Wolf HH. Involvement of a GABAergic mechanism in the pharmacologic action of phenytoin. Pharmacol. Biochem Behav 1986; 24: 1301-1304

[20] Schallert T, Jones TA, Weaver MX et al. Pharmacologic and anatomic considerations in recovery of function. Phys Med Rehabil 1992; 6: 375-393

[21] Schallert T, Hernandez TD, Barth TM. Recovery of function after brain damage: Severe and chronic disruption by diazepam. Brain Res 1986; 379: $104-11$

[22] Brailowsky S, Knight RT, Efron R. Phenytoin increases the severity of cortical hemiplegia in rats. Brain Res 1986; 376: 71-77

[23] Watson CW, Kennard MA. The effect of anticonvulsant drugs on recovery of function following cerebral cortical lesions. J. Neurophysiol 1945; 8: 221-231

[24] Chweh AQ, Swinyard EA, Wolf HH. Involvement of a GABAergic mechanism in the pharmacologic action of phenytoin. Pharmacol. Biochem Behav 1986; 24: 1301-1304

[25] Hernandez TD, Holling LC. Disruption of behavioural recovery by the anti-convulsant Phenobarbital. Brain Res 1994; 635: 300-306

[26] Gold P, Delanoy R, Merrin J. Modulation of long-term potentiation by peripherally administered amphetamine and epinephrine. Brain Res 1984; 305: 103-107

[27] Goldstein LB. Influence of common drugs and related factors on stroke outcome. Curr Opin Neurol 1997; 10: 52-57

[28] Bütefish CM, Davis BC, Sawaki L et al. Modulation of use-dependent plasticity by d-amphetamine. Ann Neurol 2002; 51: 59-68

[29] Dinse HR, Ragert P, Pleger B et al. Pharmacological modulation of perceptual learning and associated cortical reorganization. Science 2003; 301: 91-94 
[30] Crisostomo EA, Duncan PW, Propst M et al. Evidence that amphetamine with physical therapy promotes recovery of motor function in stroke patients. Ann Neurol 1988; 23: 94-97

[31] Gladstone D, Danells C, Armest A et al. Physiotherapy coupled with dextroamphetamine for rehabilitation after hemiparetic stroke: $\mathrm{A}$ randomized, double-blind, placebo controlled trial. Stroke 2006; 37: 179-185

[32] Gladstone D, Danells C, Armesto A et al. Physiotherapy coupled with dextroamphetamine for rehabilitation after hemiparetic stroke. Stroke 2006; 179-185

[33] Martinsson L, Eksborg S, Wahlgren N. Intensive early physiotherapy combined with dexamphetamine treatment in severe stroke: A randomized, controlled pilot study. Cerebrovasc Dis 2003; 16: 338-345

[34] Martinsson L, Wahlgren NG. Safety of dexamphetamine in acute ischemic stroke. Stroke 2003; 475-481

[35] Mazagri R, Shuaib A, McPehrson M et al. Amphetamine failed to improve motor function in acute stroke. Can J Neurol Sci 1995; 22: S25

[36] Pla T, Kim IH, Engel U et al. Amphetamine fails to facilitate motor performance and to enhance motor recovery among stroke patients with mild arm paresis: interim analysis and termination of a double blind, randomised, placebo-controlled trial. Restor Neurol. Neurscience 2005; 23: 271-280

[37] Sonde L, Lökk J. Effects of amphetamine and/or L-dopa and physiotherapy after stroke - a blinded randomized study. Acta Neurol Scand 2007; 115: 55-59

[38] Sonde L, Nordström MNilsson et al A double blind placebo-controlled study of the effects of amphetamine and physiotherapy after stroke. Cerebrovasc Dis 2001; 1: 253-257

[39] Treig T, Werner C, Sachse M et al. No benefit from D-amphetamine when added to physiotherapy after stroke: A randomized, placebocontrolled study. Clin Rehabil 2003; 17: 590-599

[40] Vachalthiti R, Asavavallobh C, Nilanont $Y$ et al. Comparison of physical therapy and physical therapy with amphetamine in sonsorimotor recovery of acute stroke patiens: randomized controlled trial. J Neurol Sci 2001; 187: (Suppl 1): S253

[41] Walker-Batson D, Smith P et al. Amphetamine paired with physical therapy accelerates motor recovery after stroke, further evidence. Stroke 1995; 26: 2254-2259

[42] Walker-Batson D, Smith P et al. Amphetamine paired with physical therapy accelerates motor recovery after stroke, further evidence. Stroke 1995; 26: 2254-2259

[43] Scheidtmann K, Fries W, Müller $F$ et al. Effect of levodopa in combination with physiotherapy on functional motor recovery after stroke: A prospective, randomised, double-blind study. Lancet 2003

[44] Cramer SC, Dobkin Bh, Noser EA et al. Randomized, placebo-controlled, double-blind study of ropinirole in chronic stroke. Stroke 2009; 40: 3034-3038

[45] Breitenstein C, Flöer A, Korsukeweitz C et al. A shift of paradigm: From noradrenergic to dopaminergic modulation of learning? J Neurol Sci 2006; 248: 42-47

[46] Seniow J, Litwin T, Lesniak M et al. New aproach to the rehabilitation of post-stroke focal cognitive syndrome: Effect of levodopa combined with speech and language therapy on functional recovery from aphasia. J Neurol 2009; 283: 214-218

[47] Leeman B, Laganaro M, Chetelat-Mabillard D et al. Crossover trial of subacute computerized aphasia therapy for anomia with the addition of either levodopa or placebo. Neurorehabil Neural Repair 2011; 25: 43

[48] Restemeyer C, Weiller C, Liepert J. No effect of a levodopa single dose on motor performance and motor excitability in chronic stroke. A double-blind placebo controlled cross over pilot study. Restor Neurol Neurosci 2007; 25: 143-150
[49] Lokk J, Salman Roghani R, Delbani A. Effect of methylphenidate and/or levodopa coupled with physiotherapy on functional and motor recovery after stroke - a randomized, double-blind, placebo-controlled trial. Acta Neurol Scand 2010

[50] Masihuzzaman AM, Uddin M], Majumder S et al Effect of low dose levodopa on motor outcome of different types of stroke. Mymensingh Med J 2011; 20: 689-693

[51] Acler M, Fiaschi A, Manganotti P. Long-term levodopa administration in chronic stroke patients: A clinical and neurophysiologic single-blind placebo-controlled cross-over pilot study. Restor Neurol Neurosci 2009; 27: 277-283

[52] Rosser N, Heuschmann P, Wersching $\mathrm{H}$ et al Levodopa improves procedural motor learning in chronic stroke patients. Arch Phys Med Rehabil 2008; 89: 1633-1641

[53] Floel A, Breitenstein C, Hummel F et al Dopaminergic influences on formation of a motor memory. Ann Nerol 2005; 58: 121-130

[54] Kakuda W, Abo M, Kobayashi K et al Combination treatment of low-frequency rTMS and occupational therapy with levodopa administration: An intensive neurorehabilitative approach for upper limb hemiparesis after stroke. Int J Neorosci 2011; 121: 373-378

[55] Tran DA, Pajaro-Blazquez M, Daneault J et al Combining dopaminergic facilitation with robot-assisted upper limb therapy in stroke survivors: A focused review. Am J Phys Med Rehabil 2016; 95: 459-474

[56] Zittel S, Weiller C, Liepert J. Reboxetine improves motor function in chronic stroke. A pilot study. J Neurol 2007; 254: 197-201

[57] Wang LE, Fink GR, Diekhoff $S$ et al. Noradrenergic enhancement improves motor network connectivity in stroke patients. Ann Neurol 2011; 69: 375-388

[58] Grade C, Redford B, Chrostowski J et al. Methylphenidate in early poststroke recovery: A double-blind, placebo-controlled study. Arch Phys Med Rheabil 1998; 79: 1047-1050

[59] Plenger PM, Dixon CE, Castillo RM.et.al. Subacute methylphenidate treatment for moderate to moderately severe traumatic brain injury: A preliminary double blind placebo-controlled study. Arch Phys Med Rehabil 1996; 77: 536-540

[60] Whyte J, Hart T, Schuster $K$ et al. Effects of methylphenidate on attentional function after traumatic brain injury. A randomized, placebo controlled trial. Am J Phys Med Rehabil 1997; 76: 440-450

[61] Whyte J, Hart T, Vaccaro M et al. Effects of methylphenidate on attention deficits after traumatic brain injury. A multidiemsional, randomized, controlled trial. Am J Phys Med Rehabil 2004; 83: 401-420

[62] Kornhuber J, Weller M, Schoppmeyer K et al. Amantadine and memantine are NMDA receptor antagonists with neuroprotective properties. J Neural Transm Suppl. 1994; 43: 91-104

[63] Dolin R, Reichman RC, Madore P et al. A controlled trial of amantadine and rimantadine in the prophylaxis of influenza $A$ infection. $N$ Engl J Med 1982; 10: 580-583

[64] Schwab R, Poskanzer D, England A et al Amantadine in Parkinson's disease. JAMA 1972; 222: 792-795

[65] Nickels JL, Schneider WN, Dombovy ML et al. Clinical use of amantadine in brain injury rehabilitation. Brain Inj 1994; 8: 709-718

[66] Kraus MF, Maki PM. Effect of amantadine hydrochloride on symptoms of frontal lobe dysfunction in brain injury: case studies and review. J Neuropsychiatry Clin Neurosci 1997; 9: 222-230

[67] Kraus M, Smith G, Butters M et al. Effects of the dopaminergic agent and NMDA receptor antagonist amantadine on cognitive function, cerebral glucose metabolism and D2 receptor availability in chronic traumatic brain injury: A study using positron emission tomography (PET). Brain Inj 2005; 19: 471-479

[68] Leone H, Polsonetti BW. Amantadine for traumatic brain injury: does it improve cognition and reduce agitation? J Clin Pharm Ther 2005; 30: 101-104 
[69] Schneider WN, Drew Cates ], Wong TM et al Cognitive and behavioural efficacy of amantadine in acute traumatic brain injury: an initital double-blind placebo-controlled study. Brain Inj 1999; 13: 863-872

[70] Sawyer E, Mauro LS, Ohlinger MU. Amantadine for traumatic brain injury: does it improve cognition and reduce agitation? J Clin Pharm Ther 2006; 30: 101-104

[71] Giacino J, Whyte J, Bagierlla E et al. Placebo-controlled trial of amantadine for severe traumatic brain injury. N Engl J Med 2012; 366: 819-826

[72] Hammond FM, Sherer M, Malec JF et al. Amantadine effect on perceptions of irritability after traumatic brain injury: Results of the Amantadine Irritability Multisite Study. J Neurotrauma 2015; 32: $1230-1238$

[73] Huber W, Willmes K, Poeck K et al. Piracetam as an adjuvant to language therapy for aphasia: A randomized double-blind placebocontrolled pilot study. Arch Phys Med Rehabil 1997; 78: 245-250

[74] Kessler ], Thiel A, Karbe $\mathrm{H}$ et al. Piracetam improves activated blood flow and facilitates rehabilitation of poststroke aphasic patients. Stroke 2000; 31: 2112-2116

[75] Enderby P, Broeckx J, Hospers W et al. Effect of piracetam on recovery and rehabilitation after stroke: A double blind, placebo-controlled study. Clin Neuropharmacol 1994; 17: 320-331

[76] Greener J, Enderby P, Whurr R. Pharmacological treatment for aphasia following stroke. Editorial Group: Cochrane Stroke Group. Published Online: 12 MAY 2010. Assessed as up-to-date: 4 JUL 2001. DOI: 10.1002/14651858.CD000424

[77] Güngör L, Terzi M, Onar MK et al. Does long term use of piracetam improve speech disturbances due to ischemic cerebrovascular diseases? Brain Lang 2011; 117: 23-27

[78] Orgogozo JM. Piracetam in the treatment of acute stroke. Pharmacopsychiatry 1999; 32: 25-32

[79] Kauhanen ML, Korpelainen JT, Hiltunen P et al. Poststroke depression correlates with cognititve impairment and neurological deficits. Stroke 1999; 30: $1875-1880$

[80] Aström M, Adolfsson R, Asplund K. Major depression in stroke patients. A 3-year longitudinal study. Stroke 1993; 24: 976-982

[81] Michael J, Reding MD, Louise A et al Antidepressant therapy after stroke a double-blind trial. Arch Neurol 1986; 43: 763-765

[82] Dam M, Tonin P, De Boni A et al. Effects of fluoxetine and maprotiline on functional recovery in poststroke hemiplegic patients undergoing rehabilitation therapy. Stroke 1996; 27: 1211-1214

[83] Narushima K, Chan K, Kosier J et al. Does cognitive recovery aftertreatment of poststroke depression last? A 2-year follow-up of cognitive function associated with poststroke depression. Am J Psychiatry 2003; 160: 1157-1162

[84] Jorge RE, Robinson RG, Arndt S. Mortality and poststroke depression: A placebo-controlled trial of antidepressants. Am J Psychiatry 2003; 160: $1823-1829$

[85] Chollet F, Tardy J, Albucher JF et al. Fluoxetine for motor recovery after acute ischaemic stroke (FLAME): A randomised placebo-controlled trial. Lancet Neurol 2011; 10: 123-130

[86] Müller WE, Frankfurt aM. Normalisierung gestörter Neuroplastizitätsmechanismen als gemeinsame Endstrecke im Wirkungsmechanismus von Antidepressiva. Die besondere Rolle von Tianeptin. Psychopharmakotherapie 2016; 23: 230-238

[87] Watanabe Y, Gould E, Daniels DC et al. Tianeptine attenuates stress-induced morphological changes in the hippocampus. Eur J Pharmacol 1992; 222: 157-162

[88] Joffe RT, Lippert GP, Gray TA et al. Mood disorder and multiple sclerosis. Arch Neurol 1987; 44: 376-378
[89] Fredrikson S, Cheng Q, Jiang GX et al. Elevated suicide risk among patients with multiple sclerosis in Sweden. Neuroepidemiology 2003; 22: $146-152$

[90] Meythaler JM, Brunner RC, Johnson A et al. Amantadine to improve neurorecovery in traumatic brain injury-associated diffuse axonal injury: a pilot double-blind randomized trial. J Head Trauma Rehabil 2002; 17: 300-313

[91] Zafonte RD, Watanabe T, Mann NR. Amantadine: A potential treatment for the minimally conscious state. Brain Inj 1998; 12 : 617-621

[92] Zafonte RD, Lexell ], Cullen N. Possible applications for dopaminergic agents following traumatic brain injury: Part 2. J Head Trauma Rehabil 2001; 16: 112-116

[93] Patrick PD, Buck ML, Conaway MR et al. The use of dopamine enhancing medications with children in low response states following brain injury. Brain Inj 2003; 17: 497-506

[94] Patrick PD, Blackman JA, Mabry JL et al. Dopamine agonist therapy in low-response children following traumatic brain injury. J Child Neurol 2006; 21: 879-885

[95] Krimchansky B, Keren O, Sazbon L et al. Differential time and related appearance of signs, indicating improvement in the state of consciousness in vegetative state traumatic brain injury (VS-TBI) patients after initiation of dopamine treatment. Brain Inj 2004; 18 : 1099-1105

[96] Patrick PD, Blackman JA, Mabry JL et al. Dopamine agonist therapy in low-response children following traumatic brain injury. J Child Neurol 2006; 21: 879-885

[97] Passler MA, Riggs RV. Positive outcomes in traumatic brain injuryvegetative state: Patients treated with bromocriptine. Arch Phys Med Rehabil 2001; 82: 311-315

[98] Fridman EA, Krimchansky BZ, Bonetto M et al. Continuous subcutaneous apomorphine for severe disorders of consciousness after traumatic brain injury. Brain Inj 2010; 24: 636-641

[99] Martin RT, Whyte J. The effects of methylphenidate on command following and yes/no communication in persons with severe disorders of consciousness: A meta-analysis of n-of-1 studies. Am J Phys Med Rehabil 2007; 86: 613-620

[100] Meythaler JM, Depalma L, Devivo M] et al. Sertraline to improve arousal and alertness in severe traumatic brain injury secondary tomotor vehicle crashes. Brain Inj 2001; 15: 321-331

[101] Reinhard DL, Whyte J, Sandel ME. Improved arousal and initiation following tricyclic antidepressant use in severe brain injury. Arch Phys Med Rehabil1996 77: 80-83

[102] Teitelman E. Off-label uses of modafinil. Am J Psychiatry. 2001; 158: 1341

[103] Jha A, Weintraub A, Allshouse A et al. A randomized trial of modafinil for the treatment of fatigue and excessive daytime sleepiness in individuals with chronic traumatic brain injury. J Head Trauma Rehabil 2008; 23: 52-63

[104] Cohen SI, Duong TT. Increased arousal in a patient with anoxic brain injury after administration of zolpidem. Am J Phys Med Rehabil 2008; 87: 229-231

[105] Du B, Shan A, Zhang Y et al. Zolpidem arouses patients in vegetative state after brain injury: quantitative evaluation and indications. Am J Med Sci 2014; 347: 178-182

[106] Brefel-Courbon C, Payoux P, Ory F et al. Clinical and imaging evidence of zolpidem effect in hypoxic encephalopathy. Ann Neurol 2007; 62: 102-105

[107] Singh R, Mc Donald C, Dawson K et al. Zolpidem in a minimally conscious state. Brain Injury 2007; 22 (1): 103-106

[108] Thonnard M, Gosseries O, Demertzi A et al. Effect of zolpidem in chronic disorders of consciousness: A prospective open-label study. 2013. Funct Neurol 2013; 28: 259-264 
[109] White ], Rajan R, Rosenbaum A et al. Zolpidem and restoration of consciousness. Am J Phys Med Rehabil 2014; 93: 101-113

[110] Rammohan KW, Rosenberg JH, Lynn DJ et al. Efficacy and safety of modafinil (Provigil@) for the treatment of fatigue in multiple sclerosis: A two-centre phase 2 study. J Neurol Neurosurg Psychiatry 2002; 72: 179-183

[111] Stankoff B, Waubant E, Confavreux C et al. Modafinil for fatigue in MS: A randomized placebo-controlled double-blind study. Neurology 2005; 64: 1139-1143

[112] Weinshenker BG, Penman M, Bass B et al. A double blind, randomized,crossover trial of pemoline in fatigue associated with multiple sclerosis. Neurology 1992; 42: 1468-1471

[113] Krupp LB, Coyle PK, Doscher C et al. Fatigue therapy in multiple sclerosis: Results of a double blind, randomized, parallel trial of amantadine, pemoline, and placebo. Neurology 1995; 45: 19561961

[114] Murray TJ. Amantadine therapy for fatigue in multiple sclerosis. Can J Neurol Sci 1985; 12: 251-254

[115] Canadian MS Research Group. A randomized controlled trial of amantadine in fatigue associated with MS. Can J Neurosci 1987; 14: 273-279

[116] Cohen RA, Fisher M. Amantadine treatment of fatigue associated with multiplesclerosis. Arch Neurol 1989; 46: 676-680

[117] Asano M, Finlayson ML. Meta-analysis of three different types of fatigue management interventions for people with multiple sclerosis: exercise, education and medication. Mult Scler Int 2014; 1-12
[118] Achiron A, Givon U, Magalashvili D et al. Effect of Alfacalcidol on multiple sclerosis-related fatigue: A randomized, double-blind placebo-controlled study. Mult Scler 2015; 21: 767-775

[119] Veauthier C, Paul F. Therapie der Fatigue bei Multipler Sklerose. Ein Behandlungsalgorithmus. Nervenarzt 2016; 87: 1310-1321

[120] Kaur H, Prakash A, Meghi B. Drug therapy in stroke: From preclinical to clinical studies. Pharmacology 2013; 92: 324-334

[121] Xu SY, Pan SY. The failure of animal models of neuroprotection in acute ischemic stroke to translate to clinical efficacy. Med Sci Monit Basic Res 2013; 19: 37-45

[122] Tymianski M. Novel approaches to neuroprotection trials in acute ischemic stroke. Stroke 2013; 44: 2942-2950

[123] Rogalewski A, Schneider A, Ringelstein EB et al. Toward a multimodal neuroprotective treatment of stroke. Stroke 2006; 37: 1129-1136

[124] Muresanu D, Heiss W, Hoemberg V et al. Cerebrolysin and recovery after stroke (CARS). Stroke 2016; 47: 151-159

[125] Heiss WD, Brainin M, Bornstein NM et al. Cerebrolysin Acute Stroke Treatment in Asia (CASTA) Investigators et al. Cerebrolysin in patients with acute ischemic stroke in Asia: Results of a double-blind, placebo-controlled randomized trial. Stroke 2012; 43: 630-636

[126] Chang WH, Park C-h, Kim DY et al. Cerebrolysin combined with rehabilitation promotes motor recovery in patients with severe motor impairment after stroke. BMC Neurology 2016; 16: 31

[127] Dilg P. Theriaca- die Königin der Arzneien - Deutsche Apothekerzeitung. 1986; 126: 2677-2682 